\title{
ANALISIS KINERJA TATA KELOLA TEKNOLOGI INFORMASI PADA DINAS PERPUSTAKAAN DAN KEARSIPAN DAERAH KOTA SALATIGA MENGGUNAKAN FRAMEWORK COBIT 5.0
}

\author{
Harold Michael Rumere'), Andeka Rocky Tanaamah²), dan Melkior N. N. Sitokdana ${ }^{3)}$ \\ ${ }^{1,2}$ Program Studi S1 Sistem Informasi Fakultas Teknologi Informasi Universitas Kristen Satya Wacana \\ 1,2,3 Jl. Blotongan, Sidorejo Lor, Sidorejo, Kota Salatiga, Jawa Tengah 50714 \\ E-mail: 682014051@ @student.uksw.edu' ${ }^{1)}$,atanaamah@uksw.edu ${ }^{2}$, melkior.sitokdana@uksw.edu ${ }^{3)}$
}

\begin{abstract}
ABSTRAK
Dinas Perpustakaan dan Kearsipan Daerah Kota Salatiga telah menerapkan TI dalam proses operasionalnya seperti sistem informasi tata kelola perpustakaan, sistem informasi kearsipan serta sistem informasi kepegawaian. Keberadaan sistem informasi dalam instansi ini perlu dipelihara dan diawasi dengan baik agar sistem organisasi selaras dengan tujuan instansi. Salah satu cara untuk memastikan hal tersebut adalah dengan melakukan analisis kinerja sistem informasi. Analisis kinerja sistem informasi dapat dilakukan dengan menggunakan berbagai framework seperti COBIT, ITIL, COSO, dan sebagainya. Penelitian ini menggunakan Control Objective for Information and related Technology (COBIT) versi 5.0 adalah best practices yang menyediakan kegiatan dikelola oleh struktur organisasi TI dalam kerangka kerja yang berupa produk, agar berfokus pada eksekusi dan kontrol yang telah dibuat dari para ahli dari bidang tata kelola teknologi informasi. Praktik ini bisa memaksimalkan investasi TI, untuk menilai jika adanya kesalahan dalam memberikan ukuran yang dilakukan serta menyampaikan layanan. Oleh karena itu agar bisa mencapai target, penelitian ini dikerjakan menggunakan framework COBIT 5.0 agar dapat menganalisa suatu kinerja sistem informasi pada Dinas Perpustakaan dan Kearsipan Kota Salatiga. Hasil dari penelitian ini menunjukkan bahwa MEA01 berada pada level 5 (Optimizing Process), MEA02 berada pada level 3 (Established Process), MEA03 berada pada level 2 (Managed Process). Dalam hal ini Dinas Perpustakaan dan Kearsipan Daerah Kota Salatiga agar lebih efisien dalam penggunaan TI diperlukan penanganan pada faktor-faktor yang mempengaruhi sehingga maksimal, penggunaan TI untuk semua karyawan dalam pengoperasian Slims dan juga penanggung jawab TI untuk mengimbangi perkembangan teknologi.
\end{abstract}

Kata kunci: Tata Kelola Teknologi Informasi, Perpustakaan dan Pengarsipan, Frameworks, COBIT 5

\section{PENDAHULUAN}

Pentingnya teknologi informasi pada saat ini menjadi sarana dalam mengolah informasi organisasi pemerintahan karena teknologi informasi menjadikan efisiensi dan efektivitas dalam mendukung pekerjaan. Sekarang ini organisasi banyak menerapkan dan manfaatkan serta mengembangkan teknologi informasi supaya membantu organisasi dalam proses bisnisnya, supaya mendapatkan informasi yang relevan dan akurat agar bisa membantu dan mengambil keputusan. Dalam menerapkan teknologi informasi (TI) di suatu organisasi membutuhkan investasi yang besar dan ada pula risiko yang tinggi, agar melakukan pengawasan secara menyeluruh bisa melakukan mekanisme tata kelola yang tepat pada pemanfaatan TI. Suatu organisasi di pemanfaatan TI kinerjanya perlu di evaluasi supaya mekanisme manajemen TI nya berjalan sesuai tujuan dan proses bisnis di suatu organisasi pemerintahan yang berlaku. Di suatu organisasi evaluasi di perlukan untuk perkembangan teknologi informasi yang di terapkan agar berkontribusi dalam organisasi secara maksimal, ada beberapa Framework yang bisa diperlukan untuk melakukan evaluasi untuk pengendalian standar teknologi diantaranya ISO, COBIT, atau ITIL." COBIT 5.0 adalah Framework yang digunakan sebagai penelitian ini, guna dalam model Framework tata kelola TI yang mencangkup masalah finansial, operasional, implementasi, perencanaan dan pengawasan setiap proses TI.

Dinas Perpustakaan dan Kearsipan Daerah Kota Salatiga merupakan instansi yang telah menerapkan TI dalam proses operasionalnya seperti sistem informasi tata kelola perpustakaan, sistem informasi kearsipan, serta sistem informasi kepegawaian. Keberadaan sistem informasi dalam instansi ini perlu dipelihara dan diawasi dengan baik sehingga dapat dipastikan bahwa sistem organisasi selaras dengan tujuan instansi. Salah satu cara untuk memastikan hal tersebut adalah dengan melakukan analisis kinerja sistem informasi. Analisis kinerja sistem informasi dapat dilakukan dengan menggunakan berbagai framework Tata kelola TI. Control Objective for Information and related Technology (COBIT) versi 5.0 adalah best practices yang menyediakan kegiatan dikelola oleh struktur organisasi TI dalam kerangka kerja yang berupa produk, agar berfokus pada eksekusi dan kontrol yang telah dibuat dari para ahli dari bidang tata kelola teknologi informasi. Praktik ini bisa memaksimalkan investasi TI, untuk menilai jika adanya kesalahan dalam memberikan ukuran yang dilakukan serta menyampaikan layanan (Putra, 2014). Oleh karena 
itu agar bisa mencapai target, penelitian ini dikerjakan menggunakan framework COBIT 5.0 agar dapat menganalisis suatu kinerja sistem informasi pada Dinas Perpustakaan dan Kearsipan Kota Salatiga. Hasil dari penelitian ini diharapkan dapat memberikan rekomendasi untuk meningkatkan penyelarasan strategis, penyampaian nilai, pengelolaan risiko dan pengukuran kinerja sistem informasi.

Penelitian yang lain juga dilakukan oleh Guido Waluyan, dkk., dengan judul "Evaluasi Kinerja Tata Kelola TI Terhadap Penerapan Sistem Informasi Star click Framework COBIT 5 (Studi Kasus: PT. Telekomunikasi Indonesia, TBK Semarang). Membangun suatu sistem yang membantu perusahaan penelitian ini bertujuan agar dalam proses pengambilan keputusan yang menghubungkan para pengelola serta elemen yang terdapat di dalam perusahaan. Dari hasil penelitian yang didapatkan pada PT. Telekomunikasi Indonesia, TBK Semarang sudah menggunakan Sistem Informasi (SI) Star click yang mendukung proses penjualan menggunakan peta. Penulis membentuk kerangka kerja sebagai suatu references model, agar bisa memastikan kinerja tata kelola TI yang diterapkan aplikasi star click tersebut. Mencangkup perencanaan yang dikelola dengan baik maka diukur tingkat kapabilitasnya, monitoring dan penyesuaian baik internal maupun eksternal. Semua yang didapat pada tingkat kapabilitas level pada umumnya adalah 1,89 diketahui karena tingkat kapabilitas baru mencapai level manage process kategori fully archive (>85\%). Dengan ini perusahaan tersebut agar memenuhi sampai level 3 established process kategori fully archive bisa diharapkan memenuhi target berdasarkan rekomendasi yang ada (Waluyan \& Manuputty, 2016).

Penelitian lainnya dibuat oleh Ciptaningrum, dkk. (2015)., dengan judul "Audit Keamanan Sistem Informasi Pada Kantor Pemerintah Kota Yogyakarta Menggunakan COBIT 5". Mengetahui suatu tingkat kapabilitas keamanan sistem informasi yang ada di Pemerintah Kota Yogyakarta dilakukan penelitian tersebut. Dari penilaian tingkat kapabilitas keamanan SI di Pemerintahan Kota Yogyakarta masih belum memenuhi level yang dibutuhkan yaitu level 3, yang diakibatkan ada beberapa kendala.

Penelitian lainnya dilakukan oleh Putra (2014), dengan judul "Penerapan dan Penilaian Tata Kelola Teknologi Informasi Berdasarkan COBIT 5 Framework" pada BPK RI. Dengan membantu menerapkan tata kelola teknologi informasi standar internasional penelitian ini bertujuan untuk mengetahui tingkat kapabilitas pada biro TI BPK Putra menjelaskan bahwa tingkat kapabilitas di Biro TI BPK RI saat ini berada pada level 2 (managed process) dengan nilai 2,162 yang rinciannya adalah terdapat 1 proses pada level 0,3 proses pada 1, 22 proses pada level 2, 11 proses pada level 3, dan tidak adanya proses yang mencapai level 4 dan 5. Tata kelola TI pada BPK RI berada pada level 2 yang artinya work product yang dijalankan sesuai proses performa yang sudah ditetapkan dikelola baik itu melibatkan pengawasan, penyesuaian dan perencanaan. Mengatur dan mengontrol dengan baik (Haryanti, 2015).

Penelitian lainnya adalah proses IT Governance menggunakan COBIT 5 domain BAI di PT. POS Indonesia. Mengenai penilaian terhadap harapan Domain ini, dapat dipastikan agar solusi dapat memenuhi tujuan dari proses bisnis. Hasil dari penelitian ini adalah target level kapabilitas tata kelola dan manajemen TI sudah berada level 3 .

Dari hasil penelitian yang telah dibahas, maka pada penelitian ini dilakukan analisis kinerja sistem informasi menggunakan Framework COBIT 5.0 pada Dinas Perpustakaan dan Kearsipan Daerah Kota Salatiga.

\section{RUANG LINGKUP}

Ruang lingkup penelitian ini mencangkup sebagai berikut:

1. Cakupan permasalahannya adalah: terdapat berbagai masalah yang sering terjadi di Dinas Perpustakaan dan Kearsipan Daerah Kota Salatiga, terutama penanganan dalam sistem aplikasi yang digunakan. Oleh karena itu dilakukan analisis Kinerja Tata Kelola Teknologi Informasi menggunakan Framework COBIT 5.0.

2. Batasan penelitian ini adalah hanya fokus menganalisis Kinerja Tata Kelola menggunakan Framework COBIT 5.0 Domain MEA.

3. Hasil yang didapatkan dari penelitian ini dapat digunakan untuk mengidentifikasi risiko-risiko dan rekomendasi penanganan risiko sesuai dengan framework COBIT 5.

\section{BAHAN DAN METODE}

Berikut disajikan bahan kajian, metode dan tahapan penelitian yang dilakukan:

\subsection{Tenggang Teori}

Perkembangan peradaban manusia diiringi dengan perkembangan cara penyampaian informasi yang selanjutnya dikenal dengan istilah (Teknologi Informasi). Pada awalnya Teknologi Informasi dikembangkan manusia pada masa pra sejarah dan berfungsi sebagai sistem untuk pengenalan bentuk-bentuk yang mereka kenal, mereka menggambarkan informasi yang mereka dapatkan pada dinding-dinding gua, tentang berburu dan binatang buruannya. Sampai saat ini teknologi informasi terus berkembang tetapi penyampaian dan bentuknya sudah lebih modern.

Teknologi informasi adalah sarana dan prasarana (hardware, software, use ware) sistem dan metode untuk memperoleh, mengirimkan, mengolah, menafsirkan, menyimpan, mengorganisasikan, dan menggunakan data secara bermakna. Teknologi informasi diartikan sebagai ilmu pengetahuan dalam bidang informasi yang berbasis komputer dan perkembangannya sangat pesat. juga mengemukakan teknologi informasi adalah suatu teknologi yang digunakan untuk mengolah data. 89 
Pengolahan itu termasuk memproses, mendapatkan, menyusun, menyimpan, memanipulasi data dalam berbagai cara untuk menghasilkan informasi yang berkualitas, yaitu informasi yang relevan, akurat, dan tepat waktu (Oktarina, 2017).

Teknologi informasi merujuk pada seluruh bentuk teknologi yang digunakan untuk menciptakan, menyimpan, mengubah, dan menggunakan informasi dalam segala bentuknya. Teori yang lain juga diungkapkan oleh Williams dalam teknologi informasi merupakan sebuah bentuk umum yang menggambarkan setiap teknologi yang membantu menghasilkan, memanipulasi, menyimpan, mengomunikasikan, dan atau menyampaikan informasi. Teori pendukung yang lain menurut teknologi informasi dan komunikasi adalah segala sesuatu yang mendukung untuk merekam, menyimpan, memproses, mendapat lagi, memancar/mengantarkan dan menerima informasi (Darmawan \& Dwiharto, 2019).

Dari pendapat para ahli dapat disimpulkan bahwa teknologi informasi adalah suatu teknologi berupa (hardware, software, use ware) yang digunakan untuk memperoleh, mengirimkan, mengolah, menafsirkan, menyimpan, mengorganisasikan, dan menggunakan data secara bermakna untuk memperoleh informasi yang berkualitas.

Tata kelola Teknologi Informasi (TI) menentukan tingkat integrasi dan pengendalian organisasi atas investasi TI. Integrasi dalam hal ini merupakan keselarasan serta kesesuaian antara TI dengan aktivitasaktivitas bisnis yang lain, seperti kelembagaan, Sumber Daya Manusia (SDM), keuangan, pemasaran dan operasional. Hal ini menjadikan pengendalian atas investasi akan tertata dan terencana dengan baik. Selain itu, nilai intrinsik TI harus dimasukkan secara penuh ke dalam setiap aspek bisnis bukan hanya pada fungsi TI saja. Nilai-nilai intrinsik TI akan mempengaruhi perangkat keras (hardware), perangkat lunak (software) dan perangkat pikiran atau pengguna (brain ware). Tingkat integrasi TI akan mempunyai pengaruh dramatis pada bagaimana organisasi mendefinisikan misinya, pencapaian tujuan strategis dan mengomunikasikan visi nya untuk meningkatkan kinerjanya (Pratama, 2018).

Pengertian lain tentang IT governance yang di kenal adalah: "IT governance is the responsibility of executives and the board of directors, and consists of the leadership, organisational structures and processes that ensure that the enterprise's IT sustains and extends the organisation's strategies and objectives. "(ISACA, 2012)

Apa yang di maksud pengertian di atas adalah bahwa tata kelola teknologi informasi adalah tanggung jawab eksekutif dan dewan direksi. Ini adalah bagian yang tidak bisa dipisahkan dari tata kelola suatu perusahaan dan terdiri dari struktur kepemimpinan organisasi dalam proses yang dipastikan bahwa TI membantu dan memperlebar strategi dan tujuan organisasi.

Sedangkan menurut Weill \& Ross IT governance adalah "Specifying the decision rights and accountability framework to encourage desirable behaviour in using IT” (Putri, 2019).

Yang dimaksud adalah bisa dikatakan bahwa tata kelola TI merupakan framework yang jelas dalam tujuan akuntabilitas dan keputusan pengambilan agar membantu perusahaan dalam manfaatkan teknologi informasi.

Dari begitu banyak pengertian serta argumen dari para ahli yang melibatkan tentang IT Governances, dari setiap pengertian para ahli sering menuturkan lima yang berkaitan dengan Akuntabilitas teknologi informasi, Kepatuhan terhadap peraturan dan ketentuan teknologi informasi, Memuaskan kebutuhan dewan dan pemangku kepentingan, Mengelola risiko, Memberikan nilai bagi bisnis dan kontrol dari kerja yang dilakukan.

Framework adalah kerangka kerja yang dapat disempurnakan dengan classes yang spesifik atau dengan fungsi yang telah dirancang untuk mengatasi masalah yang dihadapi. COBIT (Control Objectives for Information and Related Technology) merupakan salah satu kerangka kerja (framework) dalam mendukung tata kelola teknologi informasi. COBIT dikembangkan oleh IT Governance Institute (ITGI) yang merupakan bagian dari Information Systems Audit and Control Association (ISACA). COBIT disusun oleh ITGI pada tahun 1996. Sampai saat ini sudah ada 5 versi COBIT yang diterbitkan, COBIT 1 diterbitkan pada tahun 1996, COBIT 2 tahun 1998, versi 3.0 di tahun 2000, COBIT 4.0 pada tahun 2005, COBIT 4.1 tahun 2007 dan terakhir adalah COBIT 5 diterbitkan tahun 2012.

COBIT (Control Objective for Information and related Technology) adalah kumpulan praktik terbaik (best practice) untuk pengelolaan teknologi informasi (IT management). COBIT versi 5 dibuat oleh The IT Governance Institute (ITGI) dan Information Systems Audit and Control Association (ISACA). COBIT 5 menjadikan manajemen teknik serta tata kelola perusahaan dalam pemikiran baru, dan menyampaikan pemahaman-pemahaman yang diterima secara global, praktik, perkakas analisis dan model untuk membantu meningkatkan kepercayaan, dan nilai dari sistem informasi. Gambar 1 merupakan 5 prinsip dasar dari COBIT 5 (Tridoyo, 2017).

1. Level 0 Incomplete Process

Proses tidak dilaksanakan atau gagal untuk mencapai tujuan prosesnya. Level ini, ada sedikit atau tidak ada sama sekali bukti dari setiap pencapaian tujuan proses.

2. Level 1 Performed Process (1 atribut)

Proses diimplementasikan untuk mencapai tujuan bisnisnya.

3. Level 2 Managed Process (2 atribut)

Proses yang diimplementasikan dikelola (planned, monitored, and adjusted) dan hasilnya ditetapkan dan dikontrol

4. Level 3 Established Process (2 atribut)

Proses didokumentasikan dan mengomunikasikan (untuk efisiensi organisasi)

5. Level 4 Predictable Process (2 atribut) 
Proses dimonitor, diukur, dan diprediksi demi mencapai hasil.

6. Level 5 Optimizing Process (2 atribut)

Proses memprediksikan kemudian ditingkatkan demi memenuhi tujuan bisnis yang relevan dan tujuan yang akan datang.

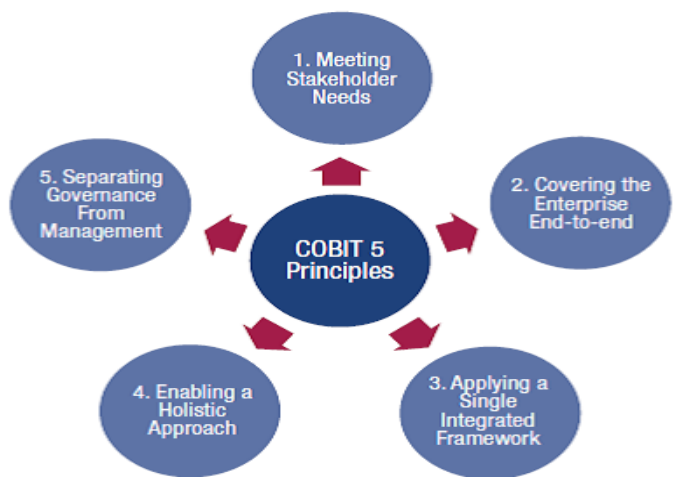

\section{Gambar 1.Prinsip-Prinsip Framework COBIT 5 (Sumber: ISACA, 2012)}

Control Objectives for Information and Related Technology (COBIT) 5.0 mempunyai 5 domain yang dibagi dalam domain governance dan management, tiaptiap domain memiliki proses agar mencapai tujuannya masing-masing, yaitu:

1. Domain Evaluate, Direct, and Monitor (EDM) terdapat 5 proses

2. Domain Align, Plan and Organize (APO) terdapat 13 proses

3. Domain Build, Acquire and Implement (BAI) terdapat 10 proses

4. Domain Deliver, Service and Support (DSS) terdapat 6 proses

5. Domain Monitor, Evaluate and Assess (MEA) terdapat 3 proses

Evaluate, Direct, and Monitor (EDM) Proses tata kelola ini berurusan dengan tujuan tata pemangku kepentingan dalam melakukan penilaian, mengoptimalkan risiko dan sumber daya, mencakup praktik dan kegiatan yang bertujuan untuk mengevaluasi pilihan strategis, memberikan arahan kepada TI dan pemantauan hasilnya.

Align, Plan and Organise (APO) Memberikan arah untuk pengiriman solusi (BAI) dan penyediaan layanan dan dukungan (DSS). Domain ini mencakup strategi dan taktik, dan mengidentifikasi kekhawatiran cara terbaik TI agar dapat berkontribusi pada pencapaian tujuan bisnis. Realisasi visi strategis perlu direncanakan, mengomunikasikan, dan dikelola untuk perspektif yang berbeda. Sebuah organisasi yang tepat, serta infrastruktur teknologi, harus dimasukkan ke dalam tempatnya.

Build, Acquire and Implement (BAI) Memberikan solusi dan melewatinya sehingga akan berubah menjadi layanan. Untuk mewujudkan strategi TI, solusi TI perlu diidentifikasi, dikembangkan atau diperoleh, serta diimplementasikan dan terintegrasi ke dalam proses bisnis. Perubahan dan pemeliharaan sistem yang ada juga dicakup oleh domain ini, untuk memastikan bahwa solusi terus memenuhi tujuan bisnis.

Deliver, Service and Support (DSS) Menerima solusi dan dapat digunakan bagi pengguna akhir. Domain ini berkaitan dengan pengiriman aktual dan dukungan layanan yang dibutuhkan, yang meliputi pelayanan, pengelolaan keamanan dan kelangsungan, dukungan layanan bagi pengguna, dan manajemen data dan fasilitas operasional.

Domain Monitor, Evaluate and Assess (MEA) yaitu berfokus pada area manajemen yaitu proses penilaian kebutuhan perusahaan dan sistem yang sedang berjalan masih memenuhi atau tidak, memastikan desain kontrol mematuhi regulasi, serta monitoring berkaitan dengan penilaian independen efektivitas sistem serta kemampuan untuk memenuhi bisnis objektif oleh penilai independen. Domain MEA terdiri dari 3 kontrol objective.

\subsection{Metode Penelitian}

Metodologi penelitian ini menggunakan metode deskriptif kualitatif. adalah merupakan salah satu dari jenis penelitian yang termasuk dalam jenis penelitian kualitatif. Adapun tujuan dari penelitian ini adalah untuk mengungkapkan kejadian atau fakta, keadaan, fenomena, variabel dan keadaan yang terjadi saat penelitian berlangsung. Penelitian ini dilakukan terhadap proses tata kelola kinerja TI yang ada pada Dinas Perpustakaan dan kearsipan Kota Salatiga. Pada penelitian ini peneliti hanya menggunakan satu domain saja yaitu domain MEA, dimana domain ini berfokus pada area manajemen yaitu proses penilaian kebutuhan perusahaan dan sistem yang sedang berjalan masih memenuhi atau tidak. Penelitian ini terdiri dari beberapa tahap, yaitu:

1. Studi Literatur

Tahap tersebut adalah proses kajian terdahulu yang relevan dan teori sebagai landasan dalam penelitian ini.

2. Pengumpulan Data

Pada tahap ini dilakukan pengumpulan data dengan berapa pendekatan, melakukan observasi selama 3 bulan di Dinas Perpustakaan dan Kearsipan Daerah Kota Salatiga agar melihat dan mengamati proses bisnis serta penggunaan aplikasi Slims. Melakukan wawancara dengan Seksi Pembinaan dalam pengoperasian aplikasi Slims.

3. Analisis Data

Pada tahap ini melakukan analisis data menggunakan Framework COBIT 5.0 dengan Domain MEA.

4. Rekomendasi dan Kesimpulan

Pada tahap ini memberikan rekomendasi dan menarik kesimpulan berdasarkan analisis data serta memberi saran. 


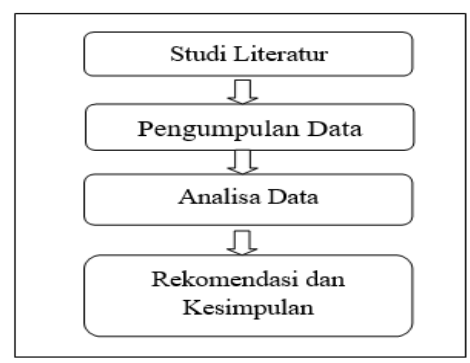

Gambar 2. Diagram Alir Penelitian

Tahapan penelitian pada Gambar 2 dapat dijelaskan sebagai berikut:

1. Tahap Pertama, mempelajari pustaka/sumber literatur mengenai COBIT Framework, tahapan evaluasi kinerja sistem informasi.

2. Tahap Kedua, melakukan pengumpulan data dimana langkah-langkah pengumpulan data akan dilakukan observasi dan wawancara, yang berlaku di Dinas Perpustakaan dan Kearsipan Daerah Kota Salatiga dan menentukan narasumber yang sesuai dengan kebutuhan dalam menjawab melakukan wawancara dengan para narasumber. Adapun alasan pemilihan narasumber adalah mereka yang dipandang memiliki keterkaitan langsung dengan bagian pelayanan di Dinas Perpustakaan dan Kearsipan Daerah Kota Salatiga.

3. Tahap Ketiga, melakukan analisis dan wawancara terhadap sistem informasi yang mengacu pada COBIT Framework pada fase ini, hasil wawancara dalam bentuk transkrip wawancara yang nantinya akan dilakukan perhitungan untuk mendapat tingkat maturity pada sistem di Dinas Perpustakaan dan Kearsipan Daerah Kota Salatiga.

4. Tahap keempat, merupakan langkah terakhir yang dilakukan adalah pembuatan laporan hasil dengan Domain MEA (Domain Monitor, Evaluate and Assess) dari kerangka kerja COBIT 5.0 dan membuat kesimpulan penelitian. Pada penelitian ini dibuat tabel RACI terlihat pada tabel 1, untuk mengidentifikasi proses dan fungsi pekerjaan yang diinginkan dalam menyelesaikan masalah, RACI adalah singkatan dari Responsible, Accountable, Consulted, dan Informed. Secara sederhana RACI menerangkan siapa saja yang terlibat dalam suatu tindakan pada sebuah organisasi baik perusahaan maupun pemerintahan.

Tabel 1. Tabel RACI

\begin{tabular}{|c|c|c|}
\hline RACI & Fungsi atau Peran & Responden \\
\hline Responsible & $\begin{array}{c}\text { Memastikan } \\
\text { aktivitas tertentu } \\
\text { berhasil } \\
\text { dilaksanakan. }\end{array}$ & $\begin{array}{c}\text { Kepala } \\
\text { Perpustakaan }\end{array}$ \\
& $\begin{array}{c}\text { kewenangan untuk } \\
\text { menyetujui atau } \\
\text { menerima }\end{array}$ & Pranata \\
& Komputer \\
& pelaksanaan & \\
\hline
\end{tabular}

\begin{tabular}{|c|c|c|}
\hline & aktivitas. & \\
\hline Consulted & Pemberi pendapat & Pranata \\
& atau yang & Komputer \\
pendapatnya & \\
& dibutuhkan dalam & \\
& sebuah aktivitas. & \\
\hline Informed & $\begin{array}{c}\text { Menjaga kemajuan } \\
\text { informasi atas }\end{array}$ & 3 Orang \\
& Pustakawan \\
& aktivitas yang & \\
dilakukan. & \\
\hline
\end{tabular}

\section{PEMBAHASAN}

Pada tahap ini mengukur tingkat kematangan pada Dinas Perpustakaan dan Kearsipan Daerah Kota Salatiga berdasarkan hasil wawancara, observasi ke setiap bagian yang terkait menggunakan COBIT 5 dengan menggunakan satu domain yaitu domain Monitor, Evaluate and Assess (MEA). Dimana domain ini terdiri dari 3 kontrol objektif yang berfokus pada area manajemen yaitu proses penilaian kebutuhan perusahaan dan sistem yang sedang berjalan masih memenuhi atau tidak, memastikan desain kontrol mematuhi regulasi, serta monitoring berkaitan dengan penilaian independen efektivitas sistem serta kemampuan untuk memenuhi bisnis objektif oleh penilaian independen.

Pemetaan kondisi saat ini Dinas Perpustakaan dan Kearsipan Daerah Kota Salatiga dilakukan dengan proses wawancara mengenai proses MEA framework COBIT 5 dengan narasumber object penelitian yaitu Dinas Perpustakaan dan Kearsipan Daerah kota Salatiga. Narasumber wawancara ditentukan berdasarkan posisi, jabatan dan tanggung jawab yang berkaitan dengan proses-proses di MEA untuk aplikasi SLiMS.

\subsection{MEA01-Monitor, Evaluate, and Assess} Performance and Conformance

Evaluasi kinerja TI khususnya aplikasi SLiMS di Dinas Perpustakaan dan Kearsipan Daerah Kota Salatiga dengan melalukan pemetaan antara tujuan bisnis dan tujuan TI, Teknologi Informasi dan strategi Perpustakaan masih standar berjalan dengan baik namun sering terjadi masalah seperti yang di sampaikan oleh Bapak Rinaldi Anggoro Shakti dari PERPUSDA Salatiga menjelaskan: " kalau aplikasi yang di gunakan itu SLiMS (Senayan Library Management System) untuk pengelolaan perpustakaan sudah termasuk standar ada berapa menu yang bisa mengakomodir kebutuhan layanan perpustakaan, tetapi kalo secara nasional memang ada aplikasi dari perpustakaan nasional yang di harapkan di pakai sehingga kemungkinan nanti mau migrasi ke program yang baru selama ini memang kinerjanya itu termasuk baik, tetapi ada beberapa yang kaitannya dengan teknis di luar aplikasi yaitu, misalnya ketika mati lampu dan sebagainya itu kurang bisa di atasi secara langsung biasanya ada trouble ketika setelah mati lampu terus gensetnya tidak menyala ketika hidup lagi nanti itu ada trouble misalnya ada beberapa menu yang tidak tampil itu termasuk administratornya itu harus 
berkonsultasi dengan dinas KOMINFO untuk meminta bantuan dari tenaga TI dan itu yang pernah terjadi. “

Berdasarkan hasil percakapan dengan Bapak Rinaldi Anggoro Shakti dari Dinas Perpustakaan dan Kearsipan Daerah Kota Salatiga dapat di katakan saat ini Kinerja TI-nya standar dan baik-baik saja, bila mana nanti PERPUSDA Salatiga migran ke program yang baru aplikasi dari perpustakaan nasional yang di harapkan bisa di pakai. Berdasarkan pemahaman tersebut maka dapat dikatakan bahwa Dinas Perpustakaan dan Kearsipan Daerah Kota Salatiga memiliki evaluasi kinerja TI yang masih standar sehingga tingkat Capability Model berdasarkan COBIT 5, Dinas Perpustakaan dan Kearsipan Daerah Kota Salatiga telah ada pada level 5 Optimizing Process.

\subsection{MEA02 - Monitor, Evaluate and Assess the System of the Internal Control}

Tujuan pengendalian internal pada Dinas Perpustakaan dan Kearsipan Daerah Kota Salatiga untuk mengatur dan menjaga standar untuk kegiatan penilaian pengendalian internal dan jaminan, seperti yang di sampaikan oleh Bapak Rinaldi Anggoro Shakti dari PERPUSDA Salatiga menjelaskan: "pengendalian internalnya begini yaitu misalnya dari hardware nya itu ditempatkan di ruang server terus yang masuk ke ruangan pengolahan untuk melakukan akses itu harus memiliki username dan password yang khusus dan hanya tau oleh admin-nya sendiri. Untuk operator dibuatkan juga password masing-masing dan untuk backup datanya itu pengendalian sendiri akan di backup setiap dua minggu."

Berdasarkan hasil percakapan dengan Bapak Rinaldi Anggoro Shakti dari Dinas Perpustakaan dan Kearsipan Daerah Kota Salatiga dapat di katakan untuk pengendalian internal nya saat ini tidak semua bisa melakukan akses pengolahan harus yang memiliki username dan password, dan untuk datanya akan terus di backup demi menjaga data tersebut ketika suatu waktu di perlukan. Berdasarkan penjelasan maka dapat dikatakan Dinas Perpustakaan dan Kearsipan Daerah Kota Salatiga memiliki tujuan pengendalian internal yang mengatur dan menjaga standar kegiatan sehingga tingkat Capability Model berdasarkan COBIT 5, Dinas Perpustakaan dan Kearsipan Daerah Kota Salatiga telah ada pada level 3 Established Process.

\subsection{MEA03-Monitor, Evaluate, and Assess Compliance with External Requirements}

Menilai proses bisnis TI pada Dinas Perpustakaan dan Kearsipan Daerah Kota Salatiga tingkat kematangan TI pada aplikasi yang digunakan, seperti yang di sampaikan oleh Bapak Rinaldi Anggoro Shakti dari PERPUSDA Salatiga menjelaskan: " untuk proses bisnis seperti saya katakan tadi menu-menu yang ada di aplikasi itu sudah menu-menu standar misalnya menu pendaftaran anggota, menu absensi kehadiran pengunjung itu juga ada, menu penelusuran atau koleksi apa saja, menu peminjaman, pengembalian, perpanjangan buku yang di pinjam kemudian menu untuk pelaporan laporan apa saja buku yang sudah di pinjam itu siapa saja yang sudah pinjam atau kelompok buku yang di pinjam apa saja dalam 1 tahun atau berapa bulan atau dalam sehari itu bisa kelihatan. Untuk stock opname perhitungan koleksi itu juga bisa di lakukan di aplikasi itu semua sudah termasuk standar."

Berdasarkan hasil percakapan dengan Bapak Rinaldi Anggoro Shakti dari Dinas Perpustakaan dan Kearsipan Daerah Kota Salatiga dapat di katakan untuk proses bensin TI yang ada itu standar di lakukan, maupun dalam melakukan perhitungan koleksi (stock opname) semuanya standar di lakukan pada aplikasi yang di gunakan. Berdasarkan pemahaman tersebut maka dapat dikatakan bahwa Dinas Perpustakaan dan Kearsipan Daerah Kota Salatiga memiliki proses bisnis TI seperti yang di katakan sehingga tingkat Capability Model berdasarkan COBIT 5, Dinas Perpustakaan dan Kearsipan Daerah Kota Salatiga telah ada pada level 2 Managed Process.

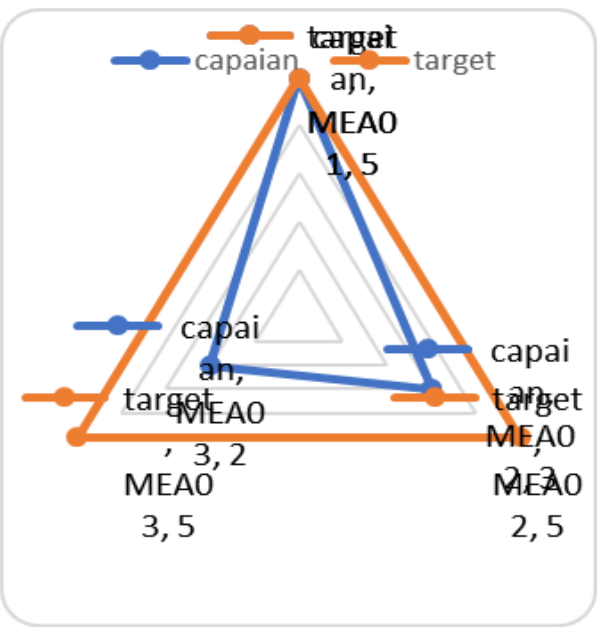

Gambar 3. Spider Chart Tingkat Kematangan

Pada gambar 3. Spider Chart tingkat kematangan sekarang. MEA01 (Monitor, Evaluate, and Assess Performance and Conformance)berada pada tingkat kematangan level 5 (Optimizing Process) karena rencana di bidang IT pada Dinas Perpustakaan dan Kearsipan Daerah Kota Salatiga, Teknologi informasi dan strategis perpustakaan sejauh ini belum sepenuhnya berjalan dengan baik. Sering terjadinya masalah yang membuat administrator harus berkonsultasi dengan Dinas KOMINFO agar dapat bantuan dari tenaga TI, perpustakaan juga menyerahkan tanggung jawab seutuhnya dalam penanggulangan server kepada KOMINFO yang mana jika terjadi penurunan kinerja server down atau kesalahan koneksi maka itu menjadi tanggung jawab KOMINFO agar ditanggulangi. Untuk permasalahan database, Dinas Perpustakaan dan Kearsipan Daerah Kota Salatiga juga telah bekerja sama 
dengan KOMINFO dalam penanggulangan server penyimpanan database, kurangnya strategis di bidang IT pada Dinas Perpustakaan dan Kearsipan Daerah Kota Salatiga masih jadi kendala saat ini. MEA02 (Monitor, Evaluate and Assess the System of the Internal Control) berada pada tingkat kematangan level 3 (Established Process) untuk pengendalian terhadap Dinas Perpustakaan dan Kearsipan Daerah Kota Salatiga. Sepenuhnya berjalan sesuai dengan strategis organisasi setiap pengolahan harus memiliki akses, untuk pengendalian data-datanya sendiri baik data buku, data peminjam dan data pegawai juga sudah mengintegrasikan dan disimpan kedalam database. Datadata itu juga akan di-backup setiap dua minggunya demi keamanan dan mencegah hal-hal yang tidak di inginkan. MEA03 (Monitor, Evaluate, and Assess Compliance with External Requirements) berada pada tingkat kematangan level 2 (Managed Process) untuk proses bisnisnya berjalan sesuai strategis pada Dinas Perpustakaan dan Kearsipan Daerah Kota Salatiga, baik dalam menu pendaftaran anggota, pengembalian dan peminjaman buku semua berjalan sesuai proses bisnis maupun dalam perhitungan koleksi (stock opname) semua standar dilakukan pada aplikasi yang di gunakan.

\subsection{Rekomendasi Proses TI}

Berdasarkan penilaian yang dilakukan pada penelitian ini oleh peneliti menggunakan Framework COBIT 5 ditemukan beberapa kekurangan yang tidak memenuhi kriteria yang ditentukan dalam Monitor, Evaluate and Assess (MEA) melalui Capability Model yang mana kurang dari tingkat kematangan level. Sebagai peneliti juga merekomendasikan dari penelitiannya tersebut yang menggunakan COBIT 5 dengan domain MEA, yang ditemukan ada beberapa permasalahan yang terjadi di Dinas Perpustakaan dan Kearsipan Daerah Kota Salatiga. Peneliti merekomendasikan setiap permasalahan yang ada dalam domain MEA sebagai alat ukur dan juga memberikan rekomendasi dari penelitiannya untuk mencapai target yang diinginkan.

Tabel 2. Tabel Rekomendasi

\begin{tabular}{|c|c|c|}
\hline $\begin{array}{c}\text { Domain } \\
\text { MEA }\end{array}$ & Permasalahan & Rekomendasi \\
\hline $\begin{array}{l}\text { MEA01 } \\
\text { (Monitoring, } \\
\text { Evaluasi dan } \\
\text { Penilaian } \\
\text { Kinerja dan } \\
\text { Kesesuaian) }\end{array}$ & $\begin{array}{l}\text { Ditemukan kelemahan } \\
\text { dalam sistem yang } \\
\text { diakibatkan banyaknya } \\
\text { pegawai yang tidak } \\
\text { dapat menggunakan } \\
\text { aplikasi Slims dengan } \\
\text { baik. Hal ini } \\
\text { disebabkan oleh karena } \\
\text { kurangnya pelatihan } \\
\text { aplikasi Slims bagi } \\
\text { para pegawai. }\end{array}$ & $\begin{array}{l}\text { Perlu adanya } \\
\text { pelatihan khusus } \\
\text { bagi para staff } \\
\text { dalam } \\
\text { mengoperasikan } \\
\text { aplikasi Slims. }\end{array}$ \\
\hline $\begin{array}{l}\text { MEA02 } \\
\text { (Monitoring, } \\
\text { Evaluasi dan }\end{array}$ & $\begin{array}{lr}\text { Hanya } & \text { melakukan } \\
\text { pengawasan } & \text { terhadap } \\
\text { infrastruktur } & \text { IT, dan }\end{array}$ & $\begin{array}{l}\text { Perlu adanya } \\
\text { peningkatan } \\
\text { dalam melakukan }\end{array}$ \\
\hline
\end{tabular}

\begin{tabular}{|c|c|c|}
\hline $\begin{array}{l}\text { Penilaian } \\
\text { Sistem } \\
\text { Kontrol } \\
\text { Internal) }\end{array}$ & $\begin{array}{l}\text { belum melakukan } \\
\text { pengawasan terhadap } \\
\text { penggunaan IT dan } \\
\text { aplikasi Slims di Dinas } \\
\text { Perpustakaan dan } \\
\text { Kearsipan Daerah Kota } \\
\text { Salatiga. }\end{array}$ & $\begin{array}{l}\text { pengawasan } \\
\text { terhadap } \\
\text { infrastruktur IT } \\
\text { dan penggunaan } \\
\text { aplikasi Slims } \\
\text { yang mana juga } \\
\text { akan berdampak } \\
\text { pada temuan. }\end{array}$ \\
\hline $\begin{array}{l}\text { MEA03 } \\
\text { (Monitoring, } \\
\text { Evaluasi dan } \\
\text { Penilaian } \\
\text { Kepatuhan } \\
\text { dan } \\
\text { Persyaratan } \\
\text { Eksternal) }\end{array}$ & $\begin{array}{l}\text { Belum memiliki } \\
\text { kebijakan-kebijakan } \\
\text { dalam penerapan IT, } \\
\text { namun sudah ada } \\
\text { pendekatan dalam } \\
\text { mengarahkan tujuan } \\
\text { penerapan IT tetapi } \\
\text { belum } \\
\text { melaksanakannya } \\
\text { secara penuh. }\end{array}$ & 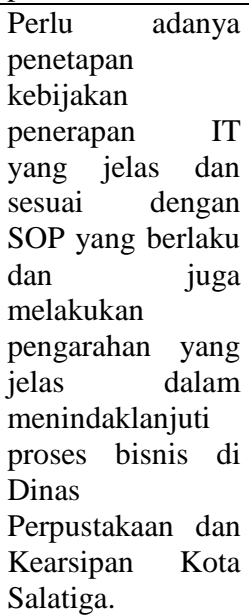 \\
\hline
\end{tabular}

\section{KESIMPULAN}

Pada penelitian ini, dari hasil Analisis Kinerja Tata kelola Teknologi Informasi menggunakan Framework COBIT 5.0 pada Dinas Perpustakaan dan Kearsipan Daerah Kota Salatiga dengan domain yang digunakan adalah Domain Monitor, Evaluate and Assess (MEA) melalui wawancara, untuk menilai tingkat kematangan (Capability Level), serta menilai kesesuaian domain MEA pada aktivitas dan tindakan yang dilakukan terkait dengan kinerja di Dinas Perpustakaan dan Kearsipan Daerah Kota Salatiga. Berdasarkan data yang diperoleh menghasilkan tingkat kematangan pada domain Monitor, Evaluate and Assess (MEA) berbeda-beda dimana pada MEA01 (Monitoring, Evaluasi dan Penilaian Kinerja dan Kesesuaian), berada pada tingkat kematangan level 5 (Optimizing Process) dimana proses memprediksikan kemudian di tingkatkan demi memenuhi tujuan bisnis. MEA02 (Monitoring, Evaluasi dan Penilaian Sistem Kontrol Internal), berada pada tingkat kematangan level 3 (Established Process) dimana proses tersebut didokumentasikan dan mengomunikasikan untuk pengendalian demi keamanan data dan akses yang ada. MEA03 (Monitoring, Evaluasi dan Penilaian Kepatuhan dan Persyaratan Eksternal), berada pada tingkat kematangan level 2 (Managed Process) dimana proses yang diimplementasikan dikelola hasil ditetapkan dan dikontrol.

\section{SARAN}

Agar dapat mencapai target yang diinginkan oleh Dinas Perpustakaan dan Kearsipan Daerah Kota Salatiga dalam penanganan peningkatan kinerja TI untuk semua karyawan pada pengoperasian aplikasi Slims, perlu 
dilakukan pelatihan khusus untuk mengimbangi perkembangan TI pada Dinas Perpustakaan dan Kearsipan Daerah Kota Salatiga.

\section{DAFTAR PUSTAKA}

Ciptaningrum, D., Nugroho, E., \& Adhipta, D. (2015, July). Audit Keamanan Sistem Informasi Pada Kantor Pemerintah Kota Yogyakarta Menggunakan COBIT 5. In Seminar Nasional Teknologi Informasi dan Komunikasi (pp. 65-74).

Darmawan, A. K., \& Dwiharto, A. 2019. Pengukuran Capability Level Kualitas Layanan E-Government Kabupaten Pamekasan Menggunakan Framework COBIT 5.0. INTENSIF: Jurnal Ilmiah Penelitian Dan Penerapan Teknologi Sistem Informasi. https://doi.org/10.29407/intensif.v3i2.12659

Haryanti, A. 2015. Pengukuran Tingkat Kapabilitas Tata Kelola Teknologi Informasi dan Rekomendasi Perbaikan Berdasarkan Kerangka Kerja COBIT 5 Studi Kasus Badan Kepegawaian Negara. 5.

ISACA. 2012. A Business Framework for the Governance and Management of Enterprise IT. In Trust And Partnership. https://doi.org/10.1002/9781119203919.ch11

Oktarina, T. 2017. Tata Kelola Teknologi Informasi Dengan COBIT 5. Jurnal Informatika.

Pratama, H. 2018. Audit Keamanan Sistem Informasi Pada Kantor Samsat Di Kota Krui Menggunakan Cobit 5. Universitas Mitra Indonesia, 2015(Sentika), $17-21$.

Putra, H. 2014. Penerapan Dan Penilaian Tata Kelola Teknologi Informasi Berdasarkan Cobit 5 Framework (Studi Kasus Pada Bpk Ri). Jurnal Teknologi Informasi UI, 1-17. http://www.lib.ui.ac.id/naskahringkas/201605/S57146-Hervandi Putra

Putri, A. D. 2019. Evaluasi Kinerja Tata Kelola Inspektorat Kota Salatiga Menggunakan Framework Cobit 5 pada Domain MEA. 682014045.

Tridoyo. 2017. Analisis Tata Kelola Teknologi Informasi E-KTP Menggunakan Framework COBIT 5 Domain DSS (Deliver, Service, Support) (Studi Kasus: Dinas Kependudukan dan Pencatatan Sipil Kabupaten Landak). 6, 5-9.

Waluyan, G., \& Manuputty, A. 2016. Evaluasi Kinerja Tata Kelola TI Terhadap Penerapan Sistem Informasi Star click Framework COBIT 5 (Studi Kasus: PT. Telekomunikasi Indonesia, TBK Semarang). Jurnal Teknologi Dan Sistem Informasi, 2, 157. https://doi.org/10.25077/TEKNOSI.v2i3.2016.157166 